\title{
CORREÇÃO DE TEXTOS: QUE RELEVÂNCIA OS PROFESSORES ATRIBUEM À ORTOGRAFIA?
}

\author{
Ana Luzia Videira Parisotto, Patrícia Regina de Souza \\ Universidade Estadual Paulista - UNESP, Pedagogia, Departamento de Educação, Campus de Presidente Prudente, E- \\ mail: analu.videira@uol.com.br \\ Órgão de fomento: CNPq
}

\section{RESUMO}

A avaliação é um aspecto inerente à prática docente, porém avaliar um texto tem se constituído como um desafio para os professores de língua portuguesa, uma vez que esta é uma tarefa complexa. O professor, muitas vezes, não sabe o que e nem como avaliar um texto e acaba dando um peso maior à dimensão gramatical, mais especificamente à correção dos erros ortográficos dos alunos. Diante disso, neste artigo, objetivamos verificar e analisar qual a importância que os docentes da Rede Municipal de Ensino de Presidente Prudente têm atribuído à ortografia quando avaliam um texto. Os resultados apontam que a ortografia se constitui como algo relevante na prática avaliativa dos professores, mas não é considerada o principal. Isso aponta para um aspecto significativo relacionado à formação docente, pois a maioria dos professores já internalizou que a ortografia é importante, mas não é o essencial.

Palavras-chave: Correção de textos. Ortografia. Ensino de Língua Portuguesa. Avaliação. Produção textual.

\section{TEXT CORRECTION: HOW RELEVANT IS SPELLING TO TEACHERS?}

\begin{abstract}
Evaluation is an essential part of the teaching practice; however, due to its complexity, evaluating a text has been a challenge to many Portuguese language teachers. Teachers often do not know what or how to evaluate a text and end up giving greater weight to the grammatical dimension, especially the correction of students' spelling mistakes. Therefore, this study aimed to investigate and analyze how important spelling was to public elementary school teachers in Presidente Prudente, Brazil, when evaluating their students' texts. The results indicate that despite construing spelling correction as a significant element of the evaluation practice, the participating teachers do not consider it of primary importance. This findings heds light on a significant aspect of Brazil's teacher education: a large amount of teachers have already internalized the idea that spelling is important but not essential.

Keywords: Text correction. Spelling. Teaching of Portuguese language. Evaluation. Text production.
\end{abstract}




\section{INTRODUÇÃO}

A prática de avaliar é um dos princípios do trabalho educativo do professor, pois a avaliação é um instrumento que diagnostica as necessidades dos alunos e é, também, um indicador de encaminhamentos necessários à prática pedagógica do docente. De acordo com Gatti (2003, p. 99) é necessário ver "[...] a avaliação em sala de aula como uma atividade contínua e integrada às atividades de ensino, algo que é decorrente destas atividades, inerente a elas e a seu serviço".

Entretanto, avaliar é uma tarefa complexa e os professores de língua portuguesa têm demonstrado dificuldades para lidar com esse aspecto no momento em que têm que avaliar um texto (COSTA VAL et al., 2009; SOUZA e LIMA, 2012; RUIZ, 1998; MARCUCHI, 2004; CONCEIÇÃO, 2004). Diante da dificuldade, os professores têm se apoiado na prática de avaliar textos levando em consideração apenas a dimensão gramatical. Todavia, existem alternativas para se avaliar um texto de modo que não haja uma avaliação simplista que reduz o texto à dimensão gramatical, mas que leve em consideração o texto em sua totalidade.

Nessa linha de pensamento, quanto à correção de textos, Costa Val et al. (2009) afirma que o professor deve se pautar em critérios que garantam que o texto seja considerado em sua complexidade. Ou seja, conforme a autora, em um texto, deve ser levado em conta as seguintes dimensões: adequação discursiva e conceitual (adequação ao tema proposto, coerência- relação título-texto, continuidade, progressão e articulação- e consistência argumentativa) e a adequação formal (coesão, morfossintaxe, paragrafação pontuação, além da ortografia e da acentuação).

Ainda, de acordo com Costa Val et al. (2009), os aspectos que mais têm sido enfatizados na correção por parte dos professores se referem à ortografia e a acentuação, contudo, mesmo assim, os alunos têm apresentado médias baixas nesses quesitos. Isso se deve à forma como o professor tem trabalhado com esses aspectos na sala de aula. Para os autores é fundamental que o aluno compreenda o sistema ortográfico e a sua importância e o professor pode ser um facilitador nesse processo, trabalhando com o dicionário para que os alunos memorizem as grafias irregulares, levando-os a compreender (em vez de memorizar) as regras subjacentes às grafias regulares.

Morais (2009), assim como muitos autores (COLELLO, 2007; CAGLIARI, MASSINI-CAGLIARI, 1999; CAGLIARI, 2009), também partilham da concepção de Costa Val et al. (2009) quando afirma que a normas ortográficas só podem ser apropriadas pelos alunos por meio de um ensino sistemático e reflexivo, pois, para tal autor, é necessário que, de fato, se invista na ortografia. 0 que não tem acontecido, já que a ortografia não tem sido nada mais do que um objeto de avaliação na sala de aula, por meio da qual se verifica se o aluno aprendeu a escrever certo.

Diante disso, é necessário avaliar um texto em sua totalidade e passar a valorizar outros aspectos que também são componentes do texto e que têm sido negligenciados nas salas de aula. Ou seja, é necessário levar em consideração a dimensão discursiva da língua que abre inúmeras possibilidades para que o usuário possa escolher, dentre a diversidade de textos, aquele texto que melhor atenda a sua necessidade de interlocução e de fala/escrita (COSTA VAL et al.;2009).

Para este artigo, o nosso objetivo será o de, dentre os cinco aspectos relevantes para correção de textos dos alunos, mencionados por ordem de importância pelos professores da Rede Municipal de Ensino de Presidente Prudente, verificar em que posição colocam a ortografia.

\section{METODOLOGIA}

Para Martins (2008), a pesquisa qualitativa é importante na medida em que possibilita a compreensão do fenômeno em estudo. Assim, de acordo com o autor, a pesquisa qualitativa corresponde a um espaço mais profundo das relações, dos processos e dos fenômenos e isso não pode ser quantificado. 
A pesquisa qualitativa é rica em informações descritivas que são obtidas no contato direto do pesquisador com o objeto de estudo, além de ser aberta e flexível, o que possibilita a focalização da realidade de uma maneira complexa e contextualizada (MARTINS, 2008).

Nessa perspectiva, nesta investigação utilizamos a abordagem qualitativa, descrevendo e analisando os fenômenos que estão impregnados dos significados que o contexto social thes concede. Dessa forma, os dados foram obtidos por meio de questionários aplicados a professores e gestores, bem como por análise documental. O projeto foi aprovado pelo Comitê de Ética em Pesquisa da Faculdade de Ciências e Tecnologia - Unesp - Presidente Prudente (Protocolo 947.980), em 06/02/2015.

A nossa amostra foi composta por professores e gestores de vinte e duas escolas municipais de Ensino Fundamental I, vinculadas à Secretaria de Educação do Município de Presidente Prudente. Os questionários destinados aos docentes foram utilizados para caracterizar o perfil pessoal, profissional e o teórico-metodológico do professor que leciona nos anos iniciais do ensino fundamental, bem como as dificuldades enfrentadas cotidianamente no ensino de língua materna, quais são as práticas formativas que consideram eficazes e como avaliam a contribuição da gestão escolar, com relação à superação do fracasso escolar em língua materna.

Este artigo é recorte dessa pesquisa maior, financiada pelo CNPq, em que analisamos as respostas dos professores quanto aos critérios que utilizavam para a correção dos textos produzidos pelos alunos. Vale ressaltar, com relação à correção de textos, que o questionário solicitava ao professor que elencasse cinco aspectos, por ordem de importância. Nesse sentido, observaremos, dentre os cinco aspectos elencados pelos docentes, em que posição colocam a ortografia.

Os dados estão sendo tabulados e analisados à luz da análise de conteúdo (BARDIN, 2011) e do referencial teórico voltado para o ensino de língua materna e formação docente (GERALDI, 2002; KOCH E TRAVAGLIA, 2008; KOCH, 2001; IMBERNÓN, 2005; MORAIS, 2009; TARDIF E LESSARD, 2008; UNESCO, 2004).

\section{RESULTADOS}

De um modo geral, destacamos que, dentre outros aspectos, a ortografia é um aspecto considerado relevante no momento em que os professores avaliam um texto. Vale ressaltar que, dos 159 docentes pesquisados, 31 não cobram a ortografia e 7 não responderam a pergunta. De tal modo, para observar a posição que a ortografia ocupava na correção de textos, analisamos a resposta de 121 professores e obtivemos 146 respostas, uma vez que, embora em posições diferentes, a resposta de 22 professores foi classificada mais de uma vez na categoria "ortografia", porque em tal categoria foram considerados elementos como: Ortografia; acentuação; segmentação das palavras; letra maiúscula e minúscula; representação da oralidade na escrita, bem como expressões correlatas.

A seguir, apresentamos uma tabela levando em consideração, dentre os cinco aspectos elencados pelos professores, por ordem de importância, a posição que a ortografia ocupa durante a avaliação de textos realizada pelos docentes do Ensino Fundamental I da rede municipal de ensino de Presidente Prudente. 
Tabela 01. Qual a importância atribuída à ortografia na correção de textos?

\begin{tabular}{ll}
\hline $\begin{array}{l}\text { Posição que a ortografia ocupa na } \\
\text { correção de textos }\end{array}$ & $\begin{array}{l}\text { Porcentagem de } \\
\text { respostas }\end{array}$ \\
\hline 1o lugar & $7,6 \%$ \\
2o lugar & $10,9 \%$ \\
3o lugar & $20,7 \%$ \\
4o lugar & $17,9 \%$ \\
5o lugar & $22,2 \%$ \\
A ortografia não é cobrada & $16,9 \%$ \\
Não responderam & $3,8 \%$ \\
\hline
\end{tabular}

Fonte: Dados organizados pelas autoras, com base nos resultados da pesquisa.

\section{DISCUSSÃO}

Com base nos resultados acima, percebe-se que $79,3 \%$ dos professores consideram a ortografia um aspecto que deve ser considerado na avaliação de um texto, porém são poucos os docentes $(7,6 \%)$ que, dentre outros aspectos, consideram a ortografia o aspecto principal na correção. Tais professores ainda constituem um grupo que tem considerado a ortografia apenas um objeto de avaliação (MORAIS, 2009) e tem desconsiderado que o texto não se reduz a sua dimensão gramatical e que existem outros aspectos (dimensão discursiva, por exemplo) que são mais importantes em um texto (COSTA VAL et al., 2009).

Vale ressaltar que as maiores porcentagens em relação à posição ocupada pela ortografia não se deu na primeira e na segunda posição, sendo as porcentagens mais altas as do terceiro $(20,7 \%)$, quarto $(17,9 \%)$ e quinto lugar $(22,2 \%)$. O que deixa claro que os professores têm se preocupado com outros aspectos do texto, mas não têm deixado de lado a correção ortográfica, já que este também é um aspecto que deve ser avaliado em um texto.

Percebe-se que $16,9 \%$ dos professores não consideram a ortografia na correção de textos. É importante destacar que, geralmente, tais docentes atuam no primeiro ano e, por ser um período inicial de alfabetização, ainda não há uma cobrança em relação a esse aspecto, uma vez que esse conteúdo ainda não é objeto de ensino. Isso se constitui como algo relevante, uma vez que para Cagliari (2009, p. 82) o período inicial de alfabetização pressupõe que o aluno saiba escrever e não que saiba escrever tudo corretamente. Ainda de acordo com o autor "Esse é um ponto importante e que relega a um segundo plano a preocupação com a ortografia durante o primeiro ano escolar".

Houve, ainda, 3,8\% dos professores que não responderam à pergunta proposta, o que pode demonstrar que a avaliação se constitui como uma dificuldade para eles, uma vez que tais docentes, talvez por insegurança, não tenham elencado os aspectos que consideram relevantes na avaliação de textos. Isso vai ao encontro de muitos estudos (COSTA VAL et al., 2009; SOUZA e LIMA; 2012; RUIZ, 1998; MARCUCHI, 2004; CONCEIÇÃO, 2004) que evidenciam que ainda existem professores que se sentem sem perspectivas e parâmetros no momento de avaliar um texto.

\section{CONCLUSÃO}

Diante dos resultados, percebemos que a ortografia é um aspecto cobrado na avaliação textual realizada pelos docentes, porém, a maioria das respostas indica que esse conteúdo não tem sido considerado o mais importante em um texto, embora não tenha sido deixado de lado. Isso aponta para um aspecto significativo relacionado à formação docente, pois a maioria dos professores já internalizou que a ortografia é um aspecto importante, mas não é o essencial. 0 
aluno precisa praticar as atividades de linguagem, ou seja, ler e escrever. A partir disso, são focalizados aspectos gramaticais e de ortografia.

Além disso, consideramos positivo o fato de os professores dos primeiros anos terem a clareza que a ortografia não é um aspecto a ser cobrado no período inicial de alfabetização. Entretanto, percebemos que ainda existem docentes inseguros com relação à prática de avaliar textos, o que demonstra que os docentes de língua portuguesa apresentam necessidades formativas para ter maior clareza de aspectos fundamentais relacionados à correção de textos.

\section{REFERÊNCIAS}

BARDIN, L. Análise de conteúdo. Lisboa: Edições 70, 2011.

CAGLIARI, L. C. Alfabetização \& Linguística. São Paulo: Scipione, 2009.

CAGLIARI, L. C; MASSINI-CAGLIARI, G. Diante das letras: a escrita na alfabetização. Campinas/SP: Mercado de Letras, 1999.

COLELLO, Silvia M. Gasparian. A escola que (não) ensina a escrever. São Paulo: Paz e Terra, 2007.

CONCEIÇÃO, R. I. S. Correção de texto: um desafio para o professor de português. Trab. Ling. Aplic., Campinas, Jul./Dez. 2004.

COSTA VAL, M. G. et al. Avaliação do texto escolar: professor-leitor/aluno-autor. Belo Horizonte/MG: Autêntica Editora/Ceale, 2009.

GATTI, B. A. O professor e a avaliação em sala de aula. Estudos em Avaliação Educacional, n. 27, jan-jun/2003.

GERALDI, J. W. A prática da leitura na escola. In: (org.). O texto na sala de aula. São Paulo: Ática, 2002.

IMBERNÓN, F. Formação docente e profissional: formar-se para a mudança e a incerteza. São Paulo: Cortez, 2005. KOCH, I. V; TRAVAGLIA, L. C. A coerência textual. 4 ed. São Paulo: Contexto, 2008.

KOCH, I. V; TRAVAGLIA, L. C. A coerência textual. 4 ed. São Paulo: Contexto, 2008.

KOCH, I. V. A coesão textual. 15 ed. São Paulo: Contexto, 2001.

MARCUSCHI, B. As categorias de avaliação textual no discurso do professor. Tese de doutorado. Recife, UFPE, 2004, $267 \mathrm{f}$.

MARTINS, J. A pesquisa qualitativa. In: FAZENDA, I. (org.). Metodologia da pesquisa educacional. São Paulo: Cortez, 2008.

MORAIS, A. G. Ortografia: ensinar e aprender. 5. ed. São Paulo: Ática, 2009.

RUIZ, E. M. S. D. Como se corrige redação na escola. Tese de doutorado. Instituto de Estudos da Linguagem, UNICAMP, 1998, $307 \mathrm{f}$. 
SOUZA, A. A. V; LIMA, A. R. As práticas avaliativas da produção textual de professoras do 5ㅇaㅇ ano do ensino fundamental. VI colóquio internacional: Educação e Contemporaneidade. São Cristovão/SE, 2012.

TARDIF, M; LESSARD, C. (org.). O ofício do professor. São Paulo: Vozes, 2008.

UNESCO. O perfil dos professores brasileiros: o que fazem, o que pensam, o que almejam. São Paulo: Moderna, 2004. 